\title{
XXVII. Analysis of some salts of mercury
}

\section{R. Phillips F.R.S. L.\&E.}

To cite this article: R. Phillips F.R.S. L.\&E. (1831) XXVII. Analysis of some salts of mercury, Philosophical Magazine Series 2, 10:57, 205-209, DOI: 10.1080/14786443108675519

To link to this article: http://dx.doi.org/10.1080/14786443108675519

曲 Published online: 14 Jul 2009.

Submit your article to this journal $\pi$

III Article views: 1

Q View related articles $\sqsubset$ 
XXVII. Analysis of some Salts of Mercury. By R. PHillips, F.R.S.L.\& E. \& c.

WHEN two parts of mercury are heated, for a short time, with three of sulphuric acid, some protosulphate of mercury is formed; but if the heat be continued, the mercury is converted almost entirely into bipersulphate, even before the evolution of sulphurous acid gas ceases, or the whole of the metal is dissolved. When this bipersulphate of mercury is put into water it is decomposed, and a yellow precipitate, formerly called turpeth mineral, is thrown down.

This salt was, I believe, first minutely examined by Fourcroy (Annales de Chimie, tom.x. p. 109.), and according to his analysis, it consists of

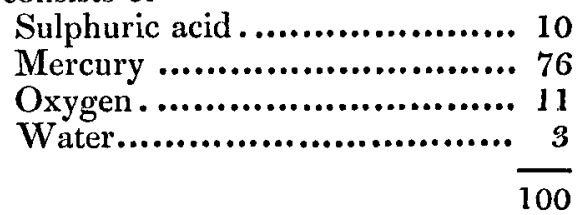

MM. Braamcamp and Sequeira (Ann. de Chimie, tom. liv. p. 123.) give as the result of their analysis,

Sulphuric acid...................... 15

Peroxide of mercury .............. 84.7

Loss, attributed to moisture ...... $00 \cdot 3$

$100 \cdot 0$

Dr. Thomson (System, vol. ii. p. 660.) observes, that supposing it to be a compound of 1 atom acid +1 atom peroxide, its constituents will be

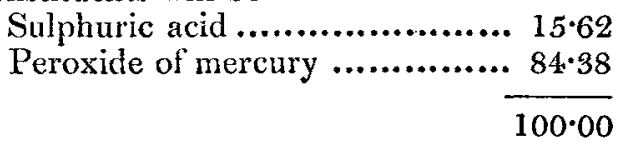

In his Attempt, \&c. (vol, ii. p. 403.) also Dr. Thomson considers this to be the true composition of this salt. Wishing, however, to determine its nature, as well as that of the salt remaining in the solution from which it is precipitated, I put 200 grains of bipersulphate of mercury into about a quart of cold water; the yellow sulphate precipitated weighed $14.1 \cdot 1$ grains; the solution was then heated, by which 8.4 grains more were obtained; afterwards sulphuretted hydrogen threw down $14 \cdot 5$ of bisulphuret of mercury.

To ascertain the composition of the yellow sulphate, I heated 100 grains in a solution of soda; the peroxide of mercury separated weighed 86.9 grains; to the solution, after supersaturation with muriatic acid, muriate of barytes was added, and 
37.5 grains of sulphate were precipitated, equivalent to 12.6 of sulphuric acid One hundred grains, therefore, yielded of

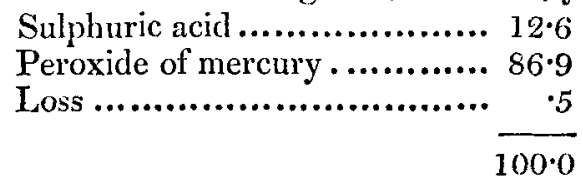

I ascertained the quantity of peroxide of mercury also, by decomposing the salt with sulphuretted hydrogen; 100 grains gave 94.8 of bisulphuret of mercury $=88.2$ of peroxide. Taking the mean of these experiments, the salt consists of

$$
\begin{array}{lll}
\text { Sulphuric acid................... } & 12 \cdot 6 \\
\text { Peroxide of mercury........... } & \frac{87 \cdot 5}{100^{\circ} 1}
\end{array}
$$

I therefore consider the yellow sulphate of mercury, as a subpersulphate constituted of

Three atoms of sulphuric acid $(40 \times 3)=120$ or $12 \cdot 2$ Four atoms of peroxide of mercury $(216 \times 4)=864 \quad 87.8$

or it may be regarded as consisting of $\overline{984} \quad \overline{100 \cdot 0}$

Two atoms of persulphate of mercury $\quad(80+432)=512$

One atom of dipersulphate.............. $(4.0+432)=4.72$

This however is so unusual an atomic constitution, that I have not admitted its existence until after repeated analyses; it will be observed, that if we add the oxygen to the mercury, in Fourcroy's analysis, the resulting peroxide will amount to 87 , with which the results of my experiments very nearly agree.

With respect to the sulphuric acid and the peroxide of mercury remaining in solution, and which have been supposed to constitute a peculiar supersalt; it may be observed, that when four atoms of bipersulphate of mercury are acted upon by water, a compound of three atoms of acid and four atoms of oxide is precipitated, while five atoms of sulphuric acid remain in solution: this acid, however, prevents the decomposition of the whole of the bipersulphate by dissolving a portion of it; the quantity remaining in solution depends, to a certain extent, upon that of the water employed; thus, when using a quart of water, as in the above related experiment, nearly 150 of the yellow subpersulphate were precipitated from 200 of the bipersulphate, but when only half the quantity of water was used, 155 were obtained from an equal 
Mr. R. Phillips's Analysis of some Salts of Mercury. 20 '7

weight : in the former experiment, therefore, about one-tenth of the bipersulphate, and in the latter rather less, remained undecomposed.

Having some reason to suppose that the compounds of carbonic acid and mercury had not been sufficiently examined, I collected all the evidence on the subject, which I have been able to obtain from the numerous authors whom I have consulted. Dr. Thomson (System, vol. ii. p. 658.) says ; "Carbonic acid does not attack mercury, but it may be combined with its oxide by pouring an alkaline carbonate into nitrate of mercury. The precipitate in that case is a white powder, composed according to Bergman of

$$
\begin{array}{lr}
\text { Mercury..................... } & 90 \cdot 9 \\
\text { Oxygen and acid........ } & \frac{9 \cdot 1}{100 \cdot 0}
\end{array}
$$

" Supposing the carbonate a compound of 1 atom carbonic acid +1 atom peroxide of mercury, it will consist of

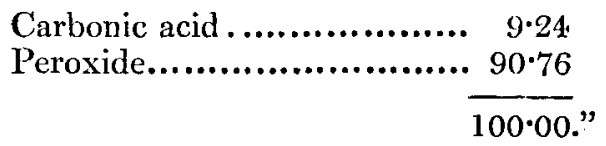

It must however be very evident that the salt obtained by Bergman was not a percarbonate so constituted; and probably it was not a percarbonate at all; for 90.9 of mercury require nearly 7.3 of oxygen for conversion into peroxide, and consequently there is left only 1.8 for carbonic acid: if we suppose it a protocarbonate, it must consist of about 90.5 protoxide and 9.5 carbonic acid; but for reasons, which I shall presently state, I am inclined to believe that it contained no carbonic acid whatever.

In his Attempt \&c. (vol. ii. p. 397.) Dr. Thomson does not mention any percarbonate of mercury; but he informs us that he obtained a white protocarbonate of mercury, by adding carbonate of soda to a solution of nitrate of mercury; the precipitate lost $14 \cdot 4.4$ per cent. by solution in nitric acid, and Dr. Thomson considers it, therefore, as a sesquiprotocarbonate of mercury, composed of

One atom and a balf of carbonic acid

One atom of protoxide of mercury

$$
\begin{array}{r}
33 \text { or } \begin{array}{l}
13 \cdot 7 \\
241
\end{array} \frac{86 \cdot 3}{100 \cdot 0}
\end{array}
$$

Although, as already mentioned, I have referred to many chemical writers, for evidence as to the existence and composition of protocarbonate oí mercury, yet except what I have quoted from Dr. Thomson, my researches have been attended 


\section{Mr. R. Phillips's Analysis of some Salts of Mercury.}

with but little success; it is indeed true, that Berzelius (Essai sur la Théorie des Proportions Chimiques, table, p. 21.) states, that what he calls carbonas hydrargyrosus, consists of 9.47 carbonic acid +90.53 protoxide of mercury, or an atom of each; but this, I take it for granted, is merely theoretical composition.

Berthollet (Mémoires d'Arcueil, tom. iii. p. 89.) after mentioning the precipitation of pernitrate of mercury, by carbonate of soda, to which I shall again advert: says, "On a fait la même expérience avec une dissolution nitrique de protoxide de mercure. Le précipité était d'un jaune clair; il a fait, après avoir été bien lavé, une vive effervescence avec l'acide nitrique. Lorsqu'on pousse fort loin les lotions, il prend une couleur noirâtre; et même sa surface se noircit lorsqu' on le laisse sous l'eau;" and he afterwards adds, "le protoxide se combine avec Iui, [l'acide carbonique, ] et peut former un carbonate, lequel cependant peut être décomposé par la seule action de l'eau qui lui enlève l'acide carbonique, quoique difficilement."

Upon considering these statements, Iapprehend that Berthollet took the yellow precipitate for a carbonate, and the black one for protoxide of mercury derived from its decomposition.

To procure protocarbonate of mercury, I mixed a solution of carbonate of potash with one of protonitrate of mercury; the precipitate at first produced was of a yellowish colour, and it remained so until excess of the alkaline carbonate was added; it then became immediately of a dark colour, and eventually as black as the precipitate formed by caustic potash: I have therefore no doubt that the yellowish precipitate, first obtained, was a subprotonitrate, and it dissolved in nitric acid without effervescence; if the solution of the nitrate be added to an excess of that of the carbonate, the precipitate is at once black.

Two hundred grains of the precipitate procured with excess of carbonate of potash, and dried by exposure to the air, were dissolved in a weighed vial of dilute nitric acid; the loss of weight was only 0.5 of a grain, and was evidently one of manipulation merely; this experiment I have repeated with similar results.

Under these circumstances, I am of opinion that a white or yellow protocarbonate of mercury cannot be formed; that when the protocarbonate is precipitated it is of a black colour, but loses its carbonic acid by drying in the air.

Berthollet states that percarbonate of mercury cannot be formed; he says indeed, correctly, that when bipermuriate of mercury is treated with carbonate of potash, it is not obtained; 
but he is wrong in supposing that a percarbonate is not procured by adding the carbonate to a solution of pernitrate: I mixed solutions of these salts and obtained a precipitate, which had an ochre yellow colour; it was dried by exposure to the air, lost $4 \cdot 4$ per cent. by dissolving in dilute ritric acid, and the solution when decumposed by soda gave 96.1 of peroxide; this salt is therefore a dipercarbonate, consisting of

Two atoms of peroxide of mercury $(216 \times 2)=432$ or 95.2 One atom of carbonic acid................... $=22 \quad 4.8$

$454 \quad 100 \cdot 0$

XXVIII. Experiments on Vanadiate of Ammonia, and on some other Compounds of Vanadium. By Mr. JoHN PRIDEAUx, Member of the Plymouth Institution.

\section{To the Editors of the Philosophical Magazine and Annals.}

\section{Gentlemen,}

IN the absence of detailed information on vanadium, a summary of experiments on the minute scale, on a portion of vanadiate of ammonia, with which $\mathbf{l}$ was favoured in a letter from Professor Berzelius, about a month since, may be not unacceptable to your chemical readers. It was accompanied by the information, that the atomic weight of vanadium is 855.87: that it combines with 1,2 and 3 atoms of oxygen, with the latter quantity forming vanadic acid; that by driving off the ammonia, in an open vessel, the acid would be obtained; and that by the same process, out of access of air, the oxide would be produced.

The acid was the first subject of experiment. It is a dull orange red powder, as described in your last Number, p. 152; and the neutral salts it forms with alkaline and earthy bases are white; which would hardly have been expected, considering the analogies of vanadium with chrome. With excess of acid, however, they are yellow.

1. Vanadiate of potash is very soluble, and showed no disposition to crystallize, although evaporated slowly to dryness, with frequent intervals of cooling, and afterwards redissolved and left to spontaneous evaporation.

2. Vanadiate of soda is scarcely so soluble, but not more disposed to crystallize.

3. The quantities employed amounting to only about 2 grains of each salt, and the indisposition to crystallize being perhaps due to the smallness of the quantity, the two solutions were mixed and abandoned to spontaneous evaporation; the glass

N.S. Vol. 10. No. 57. Sept. 1831.

$2 \mathrm{E}$

being 